\title{
Comparison of CGCM3, CSIRO MK3 and HADCM3 Models in Estimating the Effects of Climate Change on Temperature and Precipitation in Taleghan Basin
}

\author{
Arash YoosefDoost ${ }^{1, *}$, Hossein Asghari ${ }^{2}$, Reza Abunuri ${ }^{1}$, Mohammad Sadegh Sadeghian ${ }^{1}$ \\ ${ }^{1}$ Civil Engineering Department, Islamic Azad University Central Tehran Branch, Tehran, Iran \\ ${ }^{2}$ Environment Department, University of Tehran, Tehran, Iran \\ *Corresponding author: YoosefDoost@Gmail.com
}

\begin{abstract}
Climate change is a significant change in weather or in its variability in a long period. This change could be in the average of temperature, rainfall, humidity, weather patterns, wind, and sunlight and so on. Atmosphere-Ocean General Circulation Model (AOGCMs) have been developed to simulate current climate of the planet and are able to predict future climate change of the Earth. In this paper the performance of CGCM3, CSIRO Mk3 and HadCM3 models in estimating the effects of climate change on temperature and precipitation of the Taleghan basin were studied. The results show that despite relatively acceptable performance of all three models in temperature modeling, it seems that the outputs of $\mathrm{HadCM} 3$ model for this basin are more desirable when compared with CGCM3 and CSIRO MK3 models and it is can be said that HadCM3 seems to be more reliable for this basin.
\end{abstract}

Keywords: Climate Change, Atmosphere-Ocean General Circulation Model, AOGCM, CGCM3, CSIRO Mk3, HadCM3

Cite This Article: Arash YoosefDoost, Hossein Asghari, Reza Abunuri, and Mohammad Sadegh Sadeghian, "Comparison of CGCM3, CSIRO MK3 and HADCM3 Models in Estimating the Effects of Climate Change on Temperature and Precipitation in Taleghan Basin." American Journal of Environmental Protection, vol. 6, no. 1 (2018): 28-34. doi: 10.12691/env-6-1-5.

\section{Introduction}

Climate change is irreversible change in the average of weather conditions which occurs in a region. In other word, statistically significant changes in the average of weather conditions or its variability that continues over a long period. This change could be in the average of temperature, rainfall, humidity, weather patterns, wind, and sunlight. Climate could be warmer or colder and the average of values in each factor can increase or decrease over time. Some researchers consider the increase of greenhouse gases as the most important factor for gradual rise in global and oceanic temperatures. Global warming of the Earth has caused two important phenomena which are increase of global mean temperature and consequently an increase in sea level in the last hundred years. In addition in regional and local scales, climate change has had a considerable influence on precipitation, evaporation, surface runoff and extreme weather events. Industries and factories growth from the beginning of industrial revolution and consequently, fossil fuels consumption beside the destruction of forests and grasslands and change of agricultural lands usage are results of human activities and have increased the concentration of greenhouse gases particularly $\mathrm{CO}_{2}$ from $280 \mathrm{ppm}$ in 1750 to $379 \mathrm{ppm}$ in 2005. Studies show that if current trend in use of fossil fuels continues, the concentration of $\mathrm{CO}_{2}$ could reach more than $600 \mathrm{ppm}$ by the end of the twenty-first century [1]. According to the Intergovernmental report about Climate Change, the Earth's surface temperature has increased 0.3 to 0.6 degrees Celsius because of greenhouse gas emissions over the past century and it is predicted that its amount will rise to 1 to $3^{\circ} \mathrm{C}$ until 2100.

Climate change is a complex Atmospheric- oceanic and the long-term phenomenon that can be influenced by natural factors such as volcanoes, solar, ocean and atmosphere activities [2]. Many of researchers consider gradual increase in global temperature and oceans due to increase in greenhouse gases as the most important factor in climate change. Global warming of the Earth caused two important phenomena in recent century: increase in average global temperature and increase in sea level consequently, while even small changes in hydrological variables can lead to considerable changes in water resources, climate change has a considerable influence on precipitation, evaporation, surface runoff in regional and local scales [3]. The negative effects of change of climatic variables on the Earth climate and various systems has made this phenomenon which has been considered as the most dangerous problem among ten human-threatening issues in the 21 st century [4]. It is worth to say that in this classification the threat of massacre weapons stands in third place. Climate could become warmer or colder and average value of each factor of it can be increased or decreased over time. By changing climatic variables, other 
systems which are affected by these variables such as water resources, agriculture, environment, health and economy will change [4]. With the development of models and numerical tools, statistical modeling were developed by using advanced statistical methods and based on the long-term elements, phenomena and major climate causes. The investigations which are conducted by Katsoulis in 1987 [5], Karl in 1988 [6], Galbraith and Green in 1992 [7], Graf et al., 1995 [8]; Brunetti et al 2000 [9], Yuu and Hoshino in 2003 [10], Li et al. in 2004 [11] and Eyni 2014 [12] are some of related researches in this area.

IPCC provided the primary series of emission scenarios in 1992 which is called IPCC (IS92a-IS92f). In these scenarios, the amounts of greenhouse gases will increase with a fixed rate until 2100. In 1996, in order to update and replace IS92 scenarios, a series of emission scenarios called as Special Report of Emission Scenario (SRES) was published to study the climate changes. Emission scenarios were developed to explore the future developments in the global environment and provide a special reference for emission of the greenhouse gases and particulates in the atmosphere. SRES defines four main emission scenarios as A1, A2, B1 and B2 to describe the relation between the emission of greenhouse gases and suspended particles in the atmosphere and their effects on different parts of the world during the 21 st century. These scenarios have been developed based on emission factors of greenhouse gases such as population, economy, industry, energy, agriculture and land use [13].

IPCC has presented four major assessment criteria in field of climate change (FAR -1990, SAR -1995, TAR 2001 and AR4 -2007). Use of presented GCM models in AR4-2007 in climate change study has increased considerably since 2007 in comparison with presented models in previous reports. The output of these models from Data Distribution Center (DDC) is available which was established based on the proposal of task group on data and scenario support for impact and climate analysis (TGICA) in 1998 [1].

\section{Methods and Materials}

\subsection{General Circulation Models}

General Circulation Models are developed to simulate current climate on the Earth and are able to predict future climate change on the Earth [14]. These models were introduced and used based on Philips's personal investigation for the first time in the 1960s. Atmosphere General Circulation Models solve continuity equations for fluid dynamics in spatial and temporal discrete scales, and their structure is the same as numerical weather prediction models. The main difference is that in these models the weather predictions have been done in a shorter period of time (a few days) by defining the initial conditions precisely and their accuracy is limited to a regional with dimensions less than 150 kilometers. But the network which is defined for GCM may include some geographic latitude and longitude to simulate long-term weather [3].

In early GCM models, physical characteristics of the atmosphere at the Earth's surface were used as boundary conditions, but recently in these models atmosphere-ocean boundary conditions are used for ocean modeling and surface temperature and soil moisture are used for Earth's surface. One of the major weaknesses of these models is the disability to modeling the effects of clouds on the atmosphere and inadequate accuracy to express the effects of hydrological variables such as land use. In general, GCM models have better performance to simulate and predict large-scale climate events such as assessment of enormous storms rather than expression of local and regional climate processes such as rainfall-runoff process [3].

General specifications of AOGCMs, IPCC fourth Assessment Report and relevant scenarios that were used in this study are shown in Table 1.

\subsection{Downscaling}

Due to computational limitations, analysis of general climate predictions have been doing by limited centers which are equipped with specific supercomputers for these calculations. Currently, more than 40 organizations in the world have developed different models of general circulation for the planet Earth. One of the major limitations in using the output of GCM models is having large-scale computational cells in terms of their spatial and temporal which does not have required match to hydrological models. Different methods exist to produce regional climate scenarios from climate scenarios of GCM models, which are called small scaling of these methods. In proportional method usually monthly ratios are achieved for historical series. For this purpose, it is necessary to produce scenarios of climate change for temperature and precipitation at first step. In order to calculate the climate change scenario in each model, the difference values for temperature (equation (1)) and the ratio of rainfall (equation(2)) are being calculated for long-term average in each month in future periods and basic simulated periods by the model for each cell of the computational grid [15].

$$
\begin{gathered}
\Delta T_{i}=T_{G C M, \text { fut }, i}-T_{G C M, \text { base }, i} \\
\Delta P_{i}=\frac{P_{C G M, f u t, i}}{P_{C G M, o b s, i}}
\end{gathered}
$$

In the above equations $\Delta T_{i}$ and $\Delta P_{i}$ indicates climate change scenarios of temperature and precipitation for long-term average for $\mathrm{i}$ months $(12 \leq \mathrm{i} \leq 1)$, respectively. $T_{G C M, f u t, i}$ is simulation of long-term average of temperature by the GCM for $\mathrm{i}$ months in future periods, $T_{G C M, b a s e, i}$ is simulation of long-term average of temperatures by GCM in the same period with observed period for i months. $P_{C G M, f u t, i}$ is simulation of long-term average of temperature by the GCM for i month in future periods, $P_{C G M, o b s, i}$ is simulation of long-term average of temperatures by GCM in the same period with observed period for i months [16].

Because of the large computational cells in GCM models, simulation of climatic fluctuations is associated with turbulence. In order to eliminate these turbulences, usually instead of direct use of GCM data in climate 
change calculations, the long-term periodic average of data is used, then Change Factor method is used for minimizing scale of data. In Change Factor method to make careful time series of climatic scenario in future, climate change scenarios are added or multiplied in observed values.

$$
T=T_{o b s}+\Delta T
$$

$$
P=P_{o b s} \times \Delta P
$$

In the above equations, $\mathrm{T}_{\mathrm{obs}}$ and $\mathrm{P}_{\mathrm{obs}}$ are time series of observation temperature and precipitation in the base period, respectively. $\mathrm{T}$ and $\mathrm{P}$ are time series of climatic scenarios of temperature and precipitation in future period, $\Delta \mathrm{T}$ and $\Delta \mathrm{P}$ are climate change scenarios of minimized scale of temperature and precipitation.

Table 1. Specifications of Used AOGCMS in This Study in DDC Related to the IPCC Fourth Assessment Report

\begin{tabular}{ccccc}
\hline Model Name & Founder Group & Simulation Scenario & Atmospheric Separation Power & Reference \\
\hline CSIRO Mk3 & ABM (Australia) & A2, B1 & $1 / 875^{\circ} * 1 / 875^{\circ}$ & Gordon et al. (2002) [18] \\
CGCM3 & CCCMA (Canada) & A2, B1 & $3 / 75^{\circ} * 3 / 75^{\circ}$ & Kim et al. (2002, 2003) [19], [20] \\
HadCM3 & UKMO (UK) & A1FI, A2, B1 & $2 / 5^{\circ} * 3 / 75^{\circ}$ & Pope et al. (2000) [21] \\
\hline
\end{tabular}

\subsection{The Study Region}

Based on the water master plan of Iran, large SefidRood River basin is divided to 17 sub-basins and upper basin of Taleghan with $960 \mathrm{Km}^{2}$ area is located in east of SefidRood basin and covered $2.5 \%$ of its surface. The upstream of Taleghan catchment is located in central Alborz Mountains and the most important feature is its high altitude and steep slope. The average elevation of basin is 2665 meters above sea level and its maximum and minimum height is 4300 and 1390 meters, respectively. Also 50percent of Taleghan catchment has more than $40 \%$ slope and its general direction is east-west. Distribution of precipitation in its different locations varies between 250 and $1000 \mathrm{~mm}$ per year, also annual average rainfall in the entire of basin is $600 \mathrm{~mm}$. Length of Taleghan River is 85 meters, which is located in this catchment and it has its own maximum discharge in spring [17].

Considering to the time constraints of available data for rainfall, temperature and runoff in a common period in selected stations and the need for long period for using rainfall-runoff model, 1968-2008 period was chosen. Rainfall, temperature and monthly runoff data of selected basin stations were corrected and completed. To obtain the average rainfall of the basin, weighted average of the selected stations were used. Therefore, for each station weighted average was taken into based on its elevation and area and average level and total area of the basin.

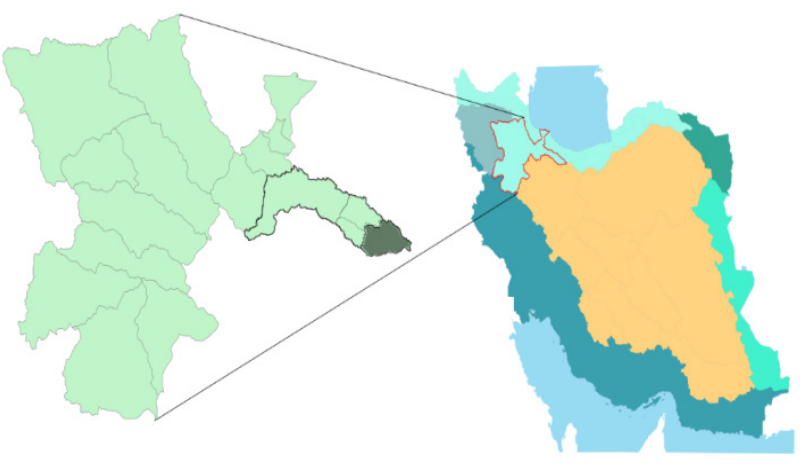

Figure 1. The Upstream Basin of Taleghan

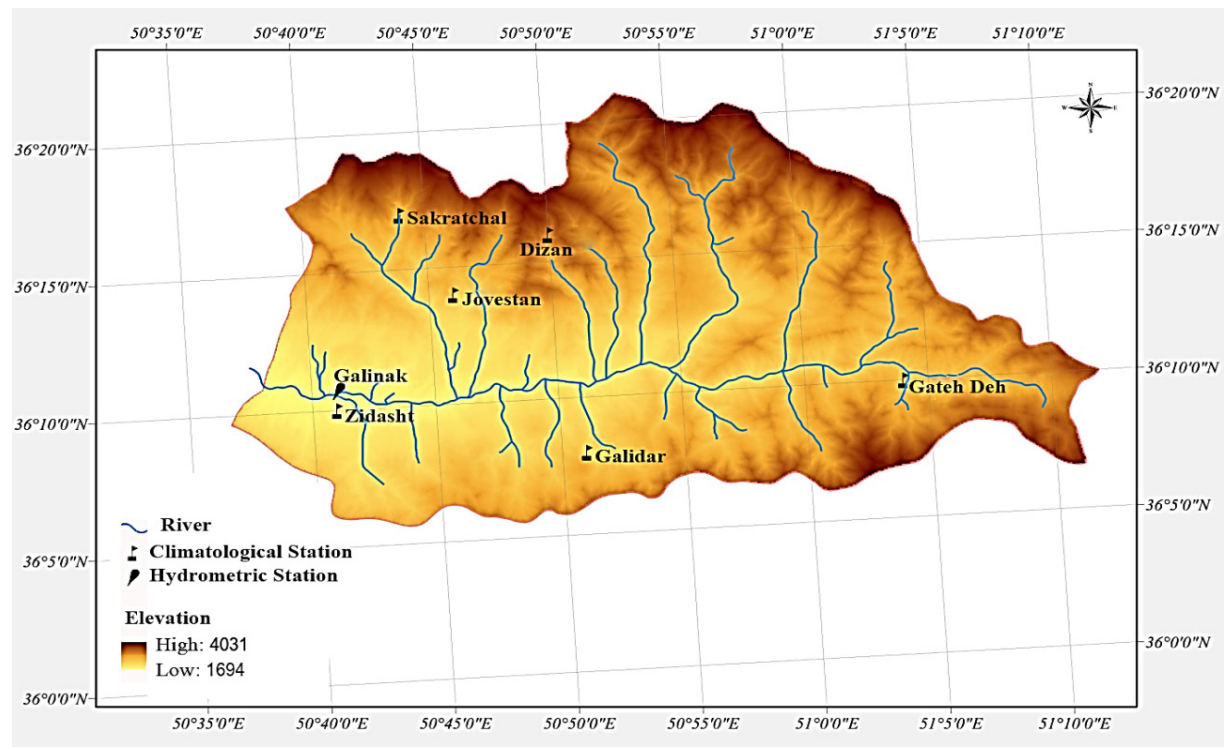

Figure 2. The Climatological and Hydrometric Stations in Upstream Basin of Taleghan 


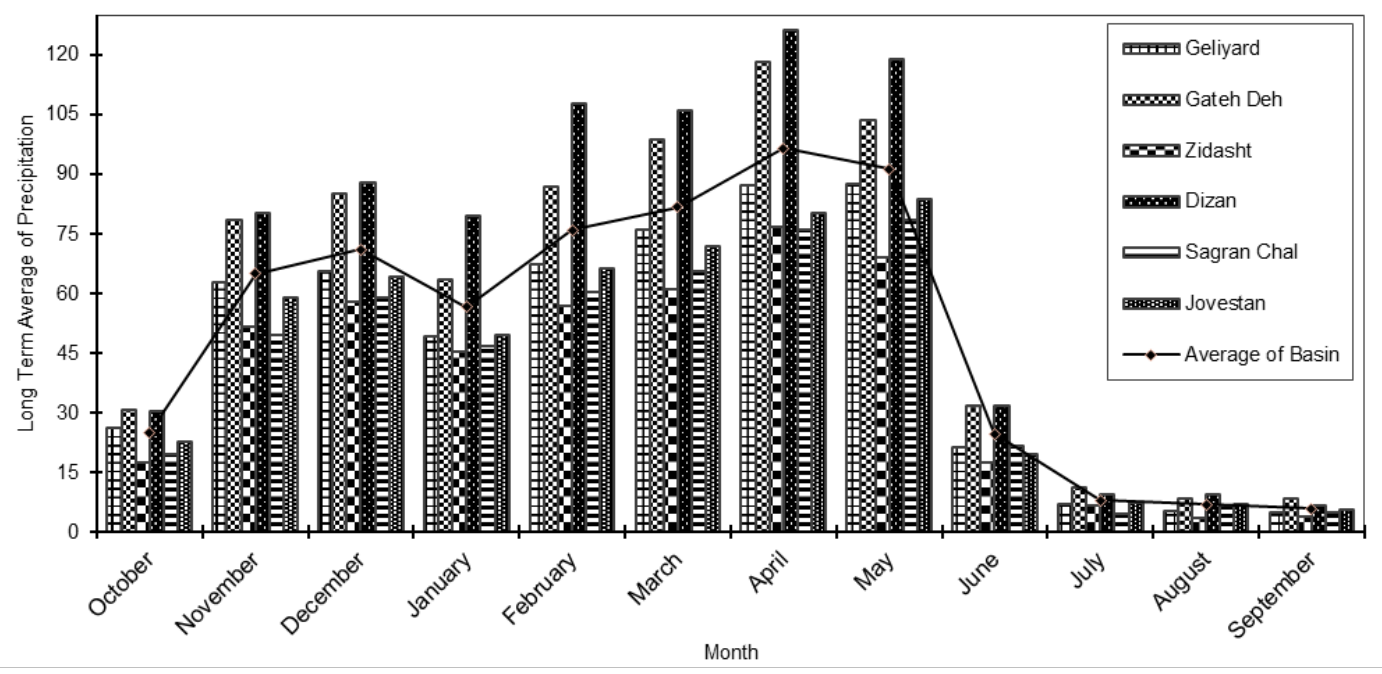

Chart 1. The Long-Term Average of Monthly Rainfall in Each Station [17]

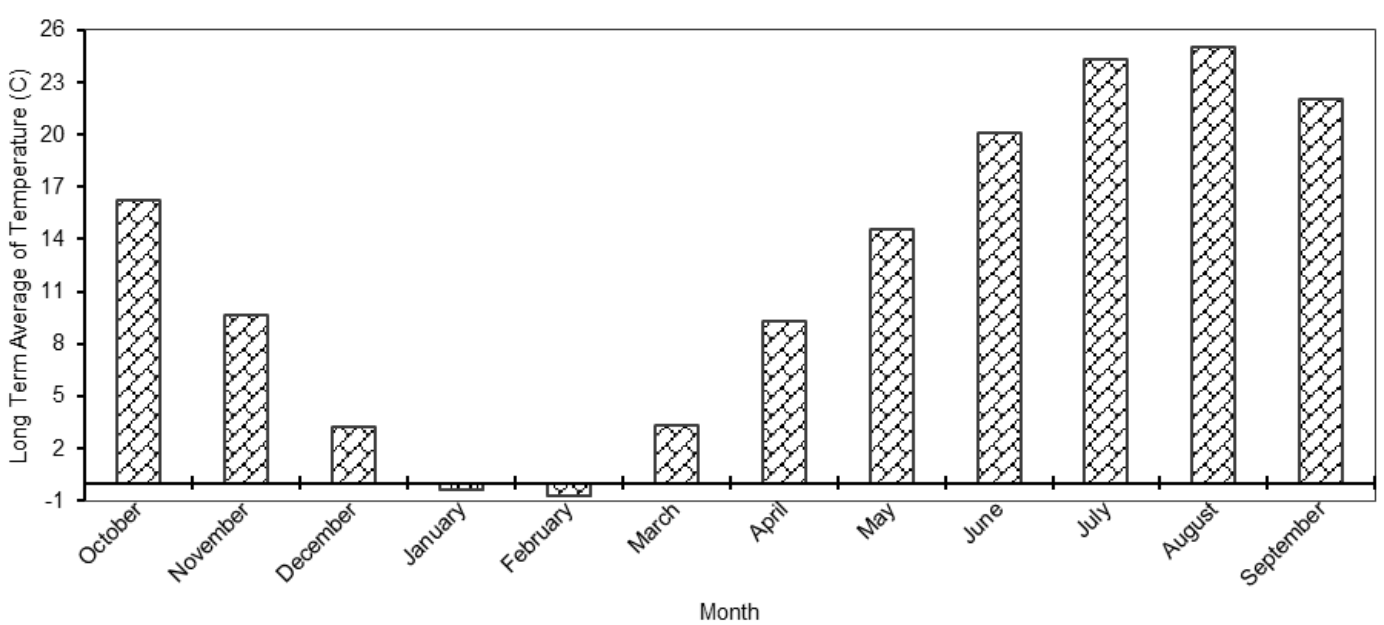

Chart 2. Long-Term Monthly Average of Temperature in Taleghan Basin [17]

According to the chart (1) the average of annual rainfall is $600 \mathrm{~mm}$ in the basin and the months with the most amount of precipitation are April and May. For all stations, winter months experience more than 45 millimeters of rainfall. Joostan, Gateh deh and Galidar precipitation stations have high impact on average rainfall and consequently on catchment runoff according to its rate of precipitation and catchment height. However, according to information of Zidasht station, the average temperature in this area is the $7.8^{\circ} \mathrm{C}$. The absolute maximum temperature is $37^{\circ} \mathrm{C}$ in July and minimum temperature is $-18^{\circ} \mathrm{C}$ which is measured in March.

As chart (2) shows, for temperature variable monthly data of Zidasht with elevation of 2000 meters due to its lowest difference elevation with the average elevation of the basin $\left(372^{\prime} 2 \mathrm{~m}\right)$, this station was considered as the basis and according to elevation difference between Ziadasht station and the average elevation of the upstream basin of Taleghan, with use of a temperature gradient and height, temperature data related average basin would be calculated.

Because of limitations in available rainfall and temperature data in the study area, 1968-2008 period which was common among all stations was chosen as the base period. In order to evaluate the performance of selected GCM models in simulation of regional climate variables, while A2 emission scenario shows stricter conditions for the status of greenhouse gas emissions in future periods than other scenarios emissions, it was considered. Then monthly precipitation and temperature data selected from GCM models that contain the timeseries variables of computational cells surrounding the Earth's climate, were taken from CCCSN, and monthly precipitation and temperature data for the base period related to computational cell which was located in selected stations of the basin (original cells) were extracted, after that, 40-years average of monthly precipitation and temperature of the cells were determined. Finally, these amounts were compared with 40 years average of monthly observed precipitation and temperature of basin in base period.

\subsection{Validation Criteria and Methods}

In statistics, correlation refers to any statistically significant relationship between two variables, Pearson correlation coefficient has been developed by Karl Pearson based on an original idea of Francis Galton, which measures linear relationship between two random variables. The correlation coefficient can have values between -1 to +1 in which if the correlation be close to +1 , correlation is more and direct, and if correlation be close 
to -1 , correlation is more but indirect and zero mean a lack of correlation. In this study, the Pearson correlation coefficient was used to compare the results of generated data with observed one based on definition for a statistical sample with n couples $\left(\mathrm{O}_{\mathrm{i}}, \mathrm{P}_{\mathrm{i}}\right)$ we have:

$$
r=\frac{\sum_{i=1}^{n}\left(O_{i}-\bar{O}\right)\left(P_{i}-\bar{P}\right)}{\sqrt{\sum_{i=1}^{n}\left(O_{i}-\bar{O}\right)^{2}} \sqrt{\sum_{i=1}^{n}\left(P_{i}-\bar{P}\right)^{2}}}
$$

The mean absolute error (MAE) is criteria to measure how much predicted results are close to desirable ones. This criterion is measurable by the following equation:

$$
\text { MAE }=\frac{1}{\mathrm{n}} \sum_{\mathrm{i}=1}^{\mathrm{n}}\left|\mathrm{O}_{\mathrm{i}}-\mathrm{P}_{\mathrm{i}}\right|
$$

Root mean square deviation (RMSD) or root mean square error (RMSE) is a common measuring criterion that is calculated from the difference between the predicted values by model or estimator and the observed data. In fact, RMSD indicates the sample standard deviation from the predicted values and the observed data. These differences are called residual when calculations are estimated from samples and are called forecast error when are predicted out of sample. RMSE is an acceptable measure to compare the prediction errors of a special variable that is measurable by the following equation:

$$
\operatorname{RMSE}=\frac{\sqrt{\sum_{\mathrm{i}=1}^{\mathrm{n}}\left(\mathrm{O}_{\mathrm{i}}-\mathrm{P}_{\mathrm{i}}\right)^{2}}}{\mathrm{n}}
$$

In all equations $\mathrm{O}_{\mathrm{i}}$ is the observed data, $\mathrm{P}_{\mathrm{i}}$ is estimated value, $\overline{\mathrm{O}}$ is the average of observational data, $\overline{\mathrm{P}}$ is the average of estimated data and $\mathrm{n}$ is the number of data.

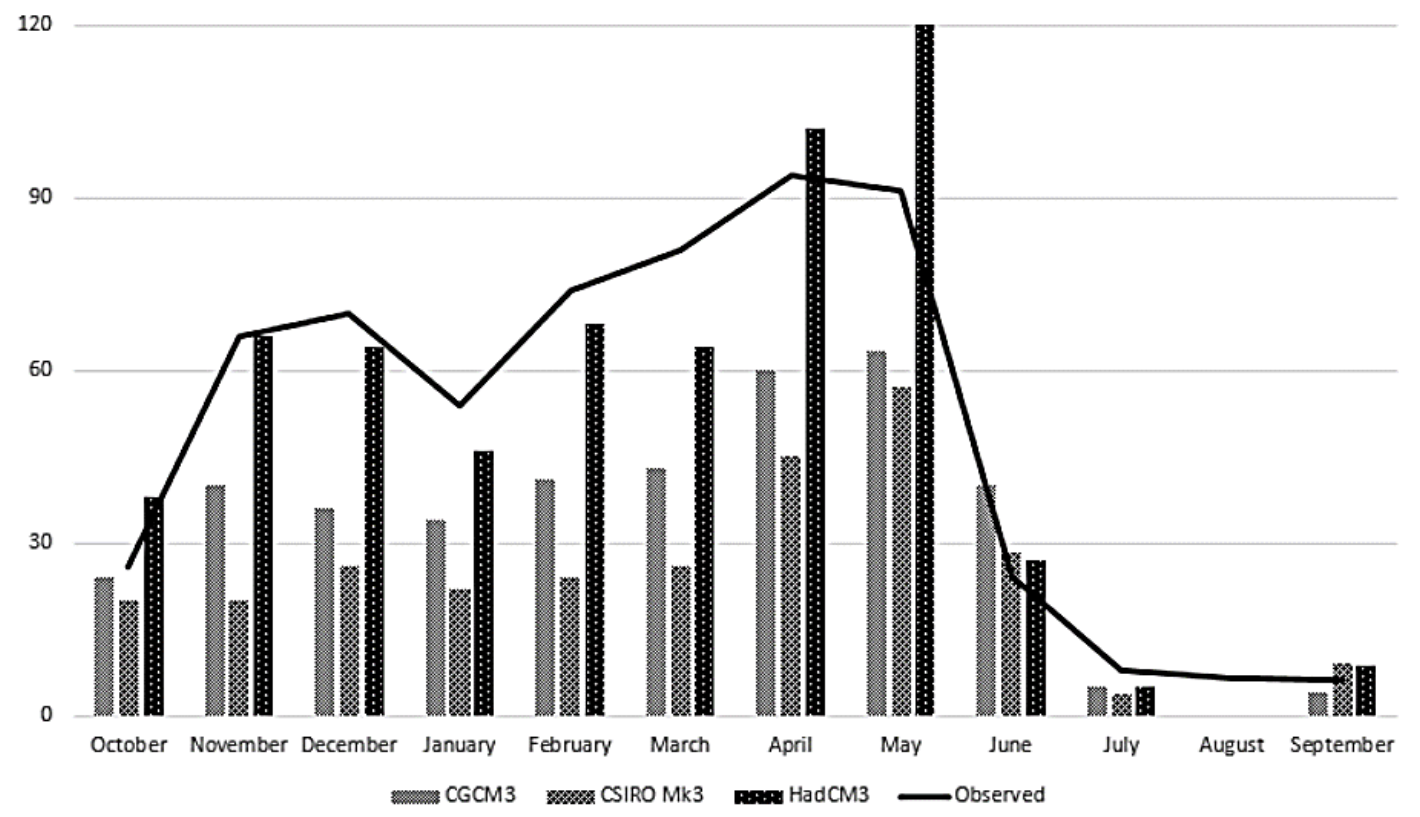

Figure 3. The long term average of precipitation: Observed vs CGCM3, CSIRO Mk3 and HadCM3 models

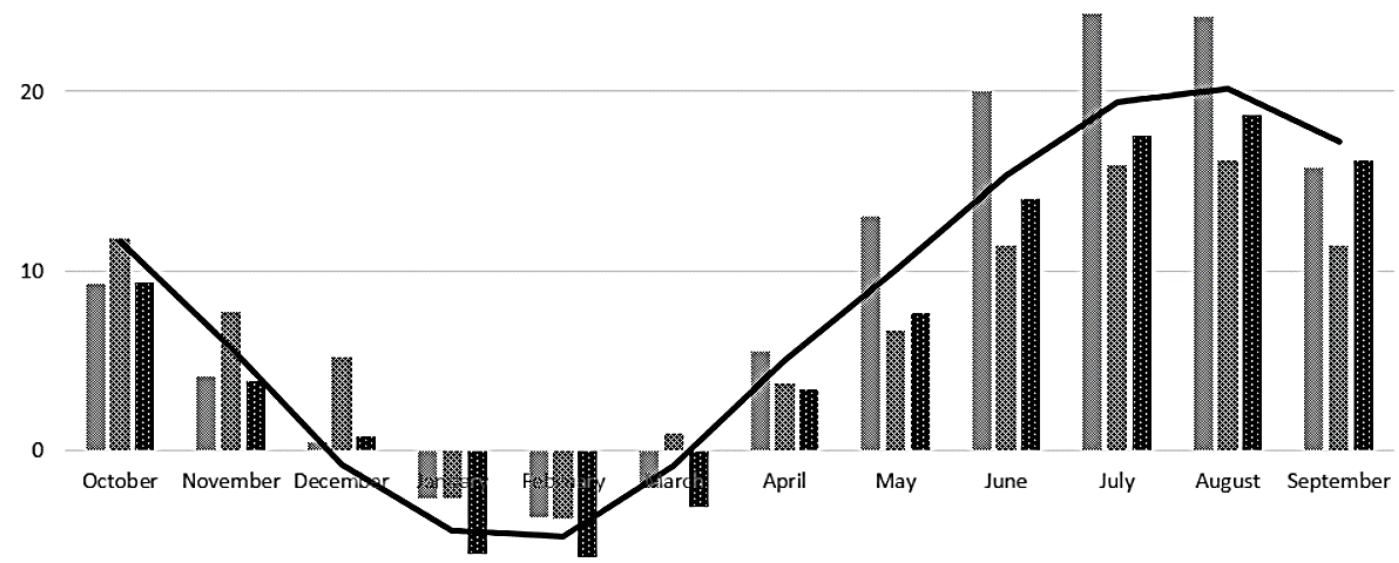

$-10$

CGCM3 CSIRO Mk3 HadCM3 Observed

Figure 4. The long term average of temperature: Observed vs CGCM3, CSIRO Mk3 and HadCM3 models 
Table 2. Validation Criteria of AOGCMs

\begin{tabular}{|c|c|c|c|c|c|c|}
\hline \multirow{2}{*}{ Model } & \multicolumn{3}{|c|}{ Rainfall } & \multicolumn{3}{|c|}{ Temperature } \\
\hline & $\mathrm{R}^{2}$ & RMSE & MAE & $\mathrm{R}^{2}$ & RMSE & MAE \\
\hline CGCM3 & 70 & 9.78 & 34.46 & 98 & 1.89 & 4.23 \\
\hline CSIRO Mk3 & 76 & 7.5 & 11.33 & 98 & 3.34 & 3.98 \\
\hline HadCM3 & 89 & 4.69 & -2.39 & 98 & 1.14 & 1.93 \\
\hline
\end{tabular}

\section{Results}

Matrices Figure 3 and shows the 40 years average of precipitation of basin in comparison with the average of the same period which is calculated by CGCM3, CSIRO Mk3 and HadCM3 models.

Figure 4 and shows the 40 years average of temperature of basin in comparison with the average of the same period which is calculated by CGCM3, CSIRO Mk3 and HadCM3 models.

Table 2 shows the validation criteria of AOGCM models in estimation the precipitation and temperature in comparison with observed data.

\section{Conclusion}

Comparison of long-term average of the results of CSIRO Mk3 and CGM 3 models with the observational dada indicates that although both models were able to estimate the general trend of rainfall in the basin, there was a dramatic difference between calculated and the long-term average of basin. Therefore, with the except of what is calculated in October, July and September which the values are partly close to the observed data, in most cases, these two models have predicted the amount of precipitation about the half of actual amount of it. In addition, although CGM3 and CSIRO Mk3 model have calculated similar amounts in October and June, in other cases they have not shown an acceptable performance.

It seems that although all studied models did not gain much success to forecast precipitation in August, HadCM3 shows better performance in comparison with two other models which have predicted considerably less amounts of precipitation for all periods, with the exception of rainfall prediction for April and May which is significantly more and for August which is close to zero.

In comparison of models performance in estimating the temperature, it seems that all of the models have been able to estimate the overall trend of temperature in a relatively acceptable pattern. CSIRO Mk3 estimated precise temperature in October, but the forecasted temperature in November, December and March are much higher than the average of basin and from April to September lower temperatures are estimated in comparison with other models. CGM3 estimated significantly high temperature from April to August in comparison with the average temperature of the basin. On the other hand, although HadCM3 estimated low temperatures for all of the time period, it anticipates favorable trend for the changes and shows relatively fewer difference in comparison with CSIRO Mk3 and CGM3.

In terms of the validation criteria, all mentioned models show high $\mathrm{R}^{2}$ and relatively low RMSE and MAE estimating the temperature which means high dependency of calculated results with observed data with low errors. However, comparison of the performance of HadCM3, CGM3 and CSIRO Mk3 models in simulation of precipitation and temperature shows that HadCM3model has better performance.

In conclusion, it can be said that in comparison of CGCM3, CSIRO Mk3 and HadCM3 models in estimation of the effects of climate change on temperature and precipitation in the Taleghan basin, although HadCM3 predicts precipitation more than the average of basin and this model predicts highest and lowest rainfall and temperature in most months respectively, it can be considered as an acceptable model that for estimating temperature and precipitation with optimal performance for climate change studies in this basin.

\section{References}

[1] IPCC 2007a, Climate Change: The Physical Science Basis Contribution of Working Group I to the Fourth Assessment Report of the Intergovernmental Panel on Climate Change. Cambridge University Press, Cambridge.

[2] J. Buchdahl, A review of contemporary and prehistoric global climate change. Chester Street, Manchester M1 5GD: Manchester Metropolitan University, 1999.

[3] S. Karamooz, M., Araghy nejad, Advanced Hydrology. Tehran: Amirkabir Technology University Press, 2005.

[4] L. O. Mearns, F. Giorgi, P. Whetton, D. Pabon, M. Hulme, and M. Lal, Guidelines for Use of Climate Scenarios Developed from. 2003.

[5] B. D. Katsoulis, "Indications of change of climate from the analysis of air temperature time series in Athens, Greece," Clim. Change, vol. 10, no. 1, pp. 67-79, Feb. 1987.

[6] T. R. Karl, "Multi-year fluctuations of temperature and precipitation: The gray area of climate change," Clim. Change, vol 12, no. 2, pp. 179-197, Apr. 1988.

[7] J. W. Galbraith and C. Green, "Inference about trends in global temperature data," Clim. Change, vol. 22, no. 3, pp. 209-221, Nov. 1992.

[8] H.-F. Graf, J. Perlwitz, I. Kirchner, and I. Schult, "Recent northern winter climate trends, ozone changes and increased greenhouse gas forcing," Contrib. Atmos. Phys., vol. 68, pp. 233-248, 1995.

[9] M. Brunetti, L. Buffoni, M. Maugeri, and T. Nanni, "Trends of Minimum and Maximum Daily Temperatures in Italy from 1865 to 1996," Theor. Appl. Climatol., vol. 66, no. 1-2, pp. 49-60, Jun. 2000.

[10] S. Yue and M. Hashino, "Temperature trends in Japang: 19001996," Environment, vol. 27, no. 1-2, pp. 15-27, 2003.

[11] Q. Li, H. Zhang, X. Liu, and J. Huang, "Urban heat island effect on annual mean temperature during the last 50 years in China," Theor. Appl. Climatol., vol. 79, no. 3-4, pp. 165-174, Dec. 2004.

[12] S. Eyni, "Investigation on comparative analysis and verification of temperature and precipitation simulations of ARIMA statistical model and MAGICC-SCENGEN climatic models (Case Study: Tabriz station)," in National Conference on Climate Change and Sustainable Development of Agriculture and Natural Resources Engineering, Science and Technology, 2014.

[13] 2000 IPCC, Emissions Scenarios. Cambridge University Press, UK.

[14] C. Xu, "From GCMs to river flow: a review of downscaling methods and hydrologic modelling approaches," Prog. Phys. Geogr., vol. 23, no. 2, pp. 229-249, Jun. 1999. 
[15] P. D. JONES and M. HULME, "CALCULATING REGIONAL CLIMATIC TIME SERIES FOR TEMPERATURE AND PRECIPITATION: METHODS AND ILLUSTRATIONS," Int. J. Climatol., vol. 16, no. 4, pp. 361-377, Apr. 1996.

[16] A. Yoosefdoost, M. Raisi, and P. Esmaeli, "Comparison of the Performance of HadCM3, GFDL CM 2.1 and CGCM3 Models in Estimating the Climate Change Effects on Rainfall and Temperature in Taleghan Basin Under SRES A2 Scenario," in The International Congress on Enviroment, 2015.

[17] A. YoosefDoost, M. Sadegh Sadeghian, M. Ali Node Farahani, and A. Rasekhi, "Comparison between Performance of Statistical and Low Cost ARIMA Model with GFDL, CM2.1 and CGM 3 Atmosphere-Ocean General Circulation Models in Assessment of the Effects of Climate Change on Temperature and Precipitation in Taleghan Basin,” Am. J. Water Resour., vol. 5, no. 4, pp. 92-99, Sep. 2017.
[18] K. H. Gordon, M. Perez, and T. E. Joiner, "The impact of racial stereotypes on eating disorder recognition," Int. J. Eat. Disord., vol 32, no. 2, pp. 219-224, Sep. 2002.

[19] S.-J. Kim, G. Flato, G. Boer, and N. McFarlane, "A coupled climate model simulation of the Last Glacial Maximum, Part 1: transient multi-decadal response," Clim. Dyn., vol. 19, no. 5-6, pp. 515-537, Aug. 2002.

[20] S.-J. Kim, G. Flato, and G. Boer, "A coupled climate model simulation of the Last Glacial Maximum, Part 2: approach to equilibrium," Clim. Dyn., vol. 20, no. 6, pp. 635-661, Apr. 2003.

[21] V. D. Pope, M. L. Gallani, P. R. Rowntree, and R. A. Stratton, "The impact of new physical parametrizations in the Hadley Centre climate model: HadAM3," Clim. Dyn., vol. 16, no. 2-3, pp. 123-146, Feb. 2000. 